\title{
Effects of nest and colony features on lesser kestrel (Falco naumanni) reproductive success
}

Maurizio Sarà ${ }^{\$}$, Daniela Campobello, Laura Zanca

Dipartimento Biologia Ambientale e Biodiversità - Università di Palermo, Via Archirafi, 18 90123 Palermo, Italy

\$corresponding author: maurizio.sara@unipa.it

\begin{abstract}
Lesser kestrel is a facultative colonial raptor mostly breeding in man-made structures. During 20092011 we checked the fate of 545 nests found in 18 colonies located in south-eastern Sicily. We determined the reproductive success of breeding pairs by analysing the survival time of each egg to hatching $(n=2495)$ and each nestling to fledging $(n=1849)$ with the Linear Hazard model of survival times. We determined whether egg and nestling survival differed between years with a Gehan-Wilcoxon test. By Cox regressions, we related the survival times with nest and colony features. Egg and nestling survival times showed a strong annual effect. The two reproductive stages of lesser kestrel when controlled for the annual effect demonstrated a significant effect for some nest and colony features. Most of them, like height from the ground, nest depth, reused nests and the presence of jackdaws, are likely related to the predation pressure faced by lesser kestrel nests. Westward and southward nests had a better egg survival respect to those in the cold sides and in the interior of buildings. The location of colony in the agricultural plain and human disturbance ranked as the most important variables, with core location of a colony and high disturbance levels negatively affecting the reproductive success of lesser kestrel in the Gela Plain, so urging a more environment-aware land use management of this Important Bird Area.
\end{abstract}

Key words: survival time analysis, egg survival, nestling survival, lesser kestrel, Falco naumanni, steppeland birds. 


\section{INTRODUCTION}

Nest survival (Dinsmore et al., 2002), the probability that a nest survives to completion by producing at least one fledging, is one of the components of bird fitness and a major parameter of avian population dynamics. Studies of nest survival aim to estimate the reproductive success of birds and therefore their annual capability to rear offspring, an indispensable element to maintain sustainable populations. Species living in grassland habitats (Vickery and Herkert, 2001; Brennan and Kuvlesky, 2005) and farmlands (Pain and Pienkowski, 1997) have been showing declining population trends. In Europe, many threatened bird species live in steppe-like habitats (Tucker and Heath, 1994), where low intensity cereal agriculture is rapidly changing as a result of intensification in farming practices and land abandonment (Donald et al., 2001). The decline of European farmland birds currently presents a major conservation challenge, therefore understanding the factors that are associated with nest survival, as well as determining the source-sink status of focal populations (Donovan et al., 1995; Bader and Bednarz, 2009), is critical for developing effective conservation and land management strategies.

Nest survival of birds may depend on several factors that include local weather and climate (Bennets et al., 2002), habitat and food quality and quantity (Peak et al., 2004; Hood and Dinsmore, 2007; Knutson et al., 2007), habitat loss, fragmentation and degradation (Drever et al., 2007; Newmark and Stanley, 2011; Saab et al., 2011), predation (Jones and Dieni, 2007; Bader and Bednarz, 2009; Liebezeit et al., 2009; Ryder et al., 2010), parasites, life history traits and individual quality of partners (Ortego et al., 2009). In the first place, nest success is, however, influenced by the nest micro- and macro-characteristics (Hansell, 2000). Raptor species that rely on human artefacts for their nest sites have been particularly susceptible to agriculture and land use changes with important repercussions on nest local availability, intra- and inter-specific competition for sites, intensity of predation (including human disturbance), and local traditions (Newton, 1979, Forero et al., 1996, Franco et al., 2005; Sarà, 2010).

The lesser kestrel (Falco naumanni) is a secondary-cavity nester, that in most of its range, breeds in urban habitats (Tella et al., 1996; Liven-Schulman et al., 2004) or in other man-made structures surrounded by open and dry cereal steppes (Serrano et al., 2001; Serrano and Tella, 2003; Franco et al., 2005; Sarà, 2010), where nests are found under roof tiles and inside balcony and wall crevices. Like most other Falco species, the lesser kestrel does not build a nest but lays its eggs directly on the cavity floor after scraping its substrate (Cramp and Simmons, 1980). This colonial raptor has undergone a dramatic decline throughout its South European and Asian range, as well as in its African wintering grounds (BirdLife International, 2004). Only recently has such a vulnerable 
species had its conservation status changed to "least concern" (IUCN, 2011), due to effective conservation actions in part of the range.

Factors that affect breeding success of lesser kestrel have been studied to some extent in Spain (Negro et al., 1993; Rodriguez and Bustamante, 1993; Forero et al., 1996) but are virtually unexplored in the remaining part of its Palaearctic breeding range. In Spanish populations, successful reproduction of both single individuals and whole colonies are perceived by conspecifics as cues to detect high quality habitats. Accordingly, the reproductive success drives dispersal by attracting more individuals toward large colonies placed in high quality habitats (Serrano and Tella, 2003). When in large colonies, potential nest cavities are all occupied, nest site availability limits the growth of lesser kestrel populations because adults prevent dispersing yearlings from joining the colony (Serrano et al., 2005a). Whether, before reaching the colony carrying capacity, individuals use cavities with sub-optimal characteristics for successful reproduction is still an open question.

Nest location can be therefore critical for nest survival of lesser kestrel and, in our knowledge no attempt has been made to test the role played by such a factor upon the reproductive performance of this species. We have hence categorized factors potentially influencing nest survival of our long-term study of a lesser kestrel population (Sarà, 2008; 2010); separating those external to the colony - i.e. 'extrinsic' - such as local weather, global climate or agricultural use around the colonies; from those directly related, - i.e. 'intrinsic' - to the colony structure itself. In this first contribution we test the relationships between nest survival and the influential intrinsic factors represented by nest and colony building characteristics.

\section{MAterial AND Methods}

\subsection{Study area}

Our study population of lesser kestrel is the largest in Sicily and one of the most important in Italy (Sarà 2010). The study area, the Gela Plain (approximately $474 \mathrm{~km}^{2}-37^{\circ} 07^{\prime} \mathrm{N} ; 1^{\circ} 20^{\prime} \mathrm{E}$ ), occurs in south-eastern Sicily, and includes a Special Protection Area (SPA, ITA050001), a Site of Community Importance (SCI, ITA050011) and is found within the Important Bird Area (IBA) no. 166 (Brunner et al., 2004). The scarce precipitation $(350 \mathrm{~mm} / \mathrm{year})$ makes this area a typical pseudo-steppe habitat, characterized by a thermo-Mediterranean dry bioclimate and surrounded by calcareous, sand and clay hills. Most territory (> 80\%) includes cropland mainly represented by wheat (Triticum spp.) and artichoke (Cynara spp.) alternated with grassland and other cultivations (E.E.A., 2000). The remaining territory $(\approx 15 \%)$ is shaped by Mediterranean maquis, small thickets of Quercus ilex and Q. suber, together with Stipa capensis garrigues, Hyparrhenia hirta grasslands 
and small artificial Eucalyptus stands. Across the plain and in the surrounding hills, numerous rural buildings, often partially destroyed or abandoned, host lesser kestrel colonies (Figure 1).

\subsection{Sampling Procedure and Data Collection}

We conducted our investigation in April - July of 2009 - 2011. Lesser kestrel nests were first identified by observing colony structures with $10 * 50$ binoculars and $20 * 60$ spotting scopes. When at least one pair of kestrels showed reproductive behaviour at the observed building (i.e. male delivering prey to female, copulation, inspection of nest chambers; Serrano et al., 2001), we proceeded to inspect potential nest-sites. Field observations and nest checks allowed us to quantify the total number of resident pairs per colony (i.e., one building hosting potentially breeding lesser kestrels).

In the three study years, we counted 789 potential breeding sites in $18 \pm 2$ colonies (per year mean \pm SD). Out of the total, in 545 nests $(69.1 \%)$ we could record at least one egg laid, while the other 244 sites were excluded from the analyses because inaccessible (i.e., they were over 6-m above the ground, out of our ladder range or in collapsing sides of buildings) or proved to be temporary roosts or laying attempts (i.e. without eggs in it).

After field observations during colony initiation and egg-laying (late March - late April), each nest was checked at least 3-4 times per season: at the time of late incubation (late April - mid May), hatching (mid May - early June) and fledging (mid June - late June); extra visits were added to account for late fledging (early July). This schedule allowed us to collect sufficient data to ascertain reproductive success while simultaneously minimizing disturbance at the reproductive sites. During nest checks, we recorded the number of eggs and nestlings inside each nest. Samples of eggs were candled for checking embryo development and incubation stage (Authors in prep.). Nestlings were aged as A1 (chick coated with first down, not standing up and not open eyes, $1-3^{\text {rd }}$ day); A2 (chick with first down, standing up and open eyes, $4-8^{\text {th }}$ day); B (chick with first down and emerged primary pins, $9-15^{\text {th }}$ day); $\mathrm{C}$ (first down in regression and outer primaries emerged $\leq 1 / 3$ of their length, 16-22 $2^{\text {nd }}$ day); D1 (large remains of first down still on head and body and outer primaries emerged $>1 / 3$ of length, 23-27 $7^{\text {th }}$ day); D2 (first down absent or little traces on head and mantle, outer primaries completely emerged, $28-32^{\text {nd }}$ day). As part of a larger investigation, captured adults and nestlings were marked with numbered aluminium and plastic coloured rings for remote identification of individuals.

We tested (see $\S 2.3$ ) the effect of the following nest features on survival: i) nest position, ii) solar exposure, iii) nest-height from the ground, iv) nest-height, v) nest-width, vi) nest-depth, vii) nest-volume, viii) use frequency. We also tested the effects of the following colony features: i) 
colony location: core vs edge of the agricultural plain, ii) colony size, iii) presence/absence of breeding jackdaw (Corvus monedula), iv) avian species richness, v) competitor/predator score, and vi) human-disturbance index.

During nest checks, the height from a ground, the height, width, depth and volume $\left(\mathrm{h}^{*} \mathrm{w}^{*} \mathrm{~d}\right)$ of a random sample of 279 nests were measured by a rigid tape measure to the nearest $1 \mathrm{~cm}(10 \mathrm{~cm}$ in the case of height from a ground). We also recorded the nest position in a hole or under tiles, and the solar exposure by a compass. Every building side was photographed with a Leica D-Lux 4. Every year, nest numbers were first chalk written on the wall beside them, and then nests were recognized on the photographs of each colony side and numbered accordingly. The comparison of photographs of colony sides allowed recording the use frequency of a given nest, i.e. new use vs reuse from the previous year. A given nest occupied in 2009, not in 2010 and again in 2011 was considered a new use.

A colony was assigned to a core location in the agricultural plain when the area of all cropland land uses summed $\geq 50 \%$ in a circular plot with radius of $500 \mathrm{~m}$ around the colony, as assessed by GIS databases of CORINE land uses digital maps (http://dataservice.eea.europa.eu/dataservice/); and to an edge location when the entire cropland area was $<50 \%$.

During lesser kestrel field observations and nest checks, we recorded the presence and breeding of jackdaw and other birds, mammals and reptiles, to collect information on the avian species richness, the competitors for the nesting space, and the predators of eggs and nestlings (Appendix 1). Broken eggs and dead nestlings were carefully examined to know the cause of loss and determine the predator species. Competitor/predator scores were attributed per annum on a 0-1 scale, with 0 representing low, 0.5 intermediate and 1 strong interference effect of other species breeding in the colony (e.g., the rock pigeon [Columba livia], a strong nest competitor, was scored as 1; while the jackdaw, a strong nest competitor plus frequent predator of lesser kestrel eggs, had a double effect, hence summing a score of 2 , etc).

Human activities in the strict proximity (i.e. 0-100 m) of colonies were also recorded annually and synthesized in a human-disturbance index for the season. This latter index resulted from the sum of a 0-3 scores (i.e., 0 lowest and 3 highest disturbance) attributed to each of seven anthropogenic variables: presence of agricultural activities/machineries; stubble-fires/wildfires; road-yards and general human activity; proximity to high speed roads; proximity to secondary roads or rural trails; presence of nest robberies/vandals/offenders; frequency of ornithological visits. 


\subsection{Statistical analysis}

In avian ecology literature, two general approaches have been used: the analysis of nest fates, by quantifying the number of nests surviving over discrete periods; and the analysis of survival times quantifying the time until nest failure (Rotella, 2007). The analysis of discrete survival data has dominated nest-survival literature (Jehnle et al., 2004; Rotella et al., 2004; Jones and Geupel, 2007; Cao et al., 2009) probably because it is also implemented in user-friendly software (Rotella, 2007). The analysis of survival times (Hosmer and Lemeshow, 1999), successfully applied to many different kinds of events across a range of disciplines, has received so far less attention from ornithologists. Nur et al. (2004) applied survival time analysis to loggerhead shrike (Lanius ludovicianus) nesting success and showed that its use is particularly powerful when explanations of nest mortality variation across the nesting period, and models of nest failure related to quantitative variables, are sought.

In our study, nest searching started at the beginning of each annual breeding season and allowed us to find virtually all the accessible nests in a colony. Nest-checks intervals were short (10-15 days) relatively to the lesser kestrel reproductive schedule and this allowed us to identify the initiation date of each nest $\left(1^{\text {st }}\right.$ laying day) with reasonable confidence. The initiation date and the day between reproductive stages were derived from both nest-checks, egg candling, aging all nestlings, and a backdating process based on 5-7 days for laying, 28-29 days for incubation and 2832 days for fledging periods (Cramp and Simmons, 1980; Serrano et al., 2001, Authors unpubl.). Unhatched or missing eggs and dead or missing nestlings were considered failed on the day corresponding to the mid-point between the last two consecutive visits (Mayfield, 1975; Serrano et al., 2001). Our data treatment avoided left-truncation (initiation date not known, early nest failures before the start of study) which is one concern for the use of survival time analysis of avian nests (Heisey et al., 2007, Jonhson, 2007). To account for possible heterogeneity in survival rate through the nesting period, we conducted one survival time analysis for each nesting stage, thus one for the incubation (including laying) and another for the brooding stage. We preferred to treat separately each egg and nestling, due to the asynchrony of incubation and hatching time of lesser kestrel (Authors unpubl.) that results in an independent fate (i.e. survival probability) of each egg and nestling. This treatment prevents the risk of introducing an underestimate of the breeding success, contrarily to more traditional survival analyses, which are based on nests as sampling units and therefore equally treat as successful nests those producing one or five nestlings.

We fitted the major theoretical survival time distributions (Exponential, Linear Hazard, Gompertz, Weibull) to eggs and nestlings data using the ordinary unweighted $\left(w_{i}=1\right.$; i.e., all weights equal to 1$)$ and weighted $\left(w_{i}=n_{i} * h_{i}\right.$ where $h_{i}$ and $n_{i}$ are the interval width and number of 
observations exposed to risk in the $i$ 'th interval, respectively) least squares method. We also determined the hazard estimate as the probability per time unit that an egg or a nestling survived to the beginning of the respective interval will fail in that interval. Two-day intervals $\left(h_{i}=2\right)$ were time slots in which the reproductive stages of lesser kestrel were divided, starting from day 0 , to compute the hazard estimate and weighted least squares. In total, 19 intervals for the 36 days of laying and incubation and 17 intervals for the 32 days of brooding were considered. We determined whether egg and nestling survival differed between years with a Gehan-Wilcoxon test by treating the study year as an independent factor and survival time as the dependent variable and quantified the effect of nest and colony characteristics (see $\S 2.2$ ) by Cox's proportional hazard regression models (Fox, 2001).

Final comparison among survival time models and significant predictors was made by the Akaike's information criterion (AIC; Akaike, 1973) and Akaike model weight $\left(w_{i}\right)$ computed on $\triangle \mathrm{AIC}$ (Conroy and Carroll, 2009). Statistical significance for all analyses was set at $\mathrm{p} \leq 0.05$, mean were reported \pm standard errors $(\mathrm{SE})$. All analyses were performed by using Statistica 8.0 for Windows (StatSoft, 2007).

\section{RESULTS}

\subsection{Egg survival time}

The cumulative proportion of surviving eggs for all years combined, was $0.738 \pm 0.009$ ( $\mathrm{n}=$ 2495 ) during the 36 days of laying and incubation (red line in Figure 2). Although they were very low for all the 2-days intervals (min: $0.0001 \pm 0.0001$; max: $0.0032 \pm 0.0013$ ), hazards rates peaked up to $0.1229 \pm 0.0052$ and $0.0216 \pm 0.0024$ at the $11^{\text {th }}$ and $12^{\text {th }}$ intervals, respectively. This indicated a heavy egg failure occurred after the second week of incubation (i.e., 20-23 day after the first laying day) in both 2009 and 2011 (Figure 2). The cumulative proportion of surviving eggs best fitted to a Linear Hazard model, showing a decline of egg survival times (Figure 3) with better (lower AIC) parameter estimates of the weighted (Lambda $=0.001535 \pm 0.000125$; $\mathrm{AIC}=6319.93$ ) distribution than the unweighted (Lambda $=0.003407 \pm 0.000212 ; \mathrm{AIC}=6398.08)$.

Eggs survival time significantly differed across years $\left(\mathrm{Chi}^{2}{ }_{(3)}=97.70 ; \mathrm{p}<0.001\right)$, with the highest survival proportion of 0.870 in 2010 and the lowest survival proportion in 2009 (0.700) and 2011 (0.669). We therefore conducted successive analyses per year, thus by taking into account the annual effect (i.e., analyses were stratified by year with same $\beta$-vectors of regression coefficients, different baseline hazard functions h0, n groups: 3 ).

Egg survival time was influenced by only 2 out 8 of the nest characteristics (Table 1), the nest height from the ground and the solar exposure with highest and westward/southward nests enjoying 
longer survival times. More colony characteristics (4 out 6) affected egg survival times (Table 1), which were longer in the colonies with high avian richness values and low human disturbance. Further, absence of jackdaws and colony locations at the edge of the agricultural plain positively affected the survival of eggs.

Among both nest and colony features, colony location outweighed all the others for the relative importance of its effect on egg survival (Table 2, Figure 3).

\subsection{Nestling survival time}

The cumulative proportion of surviving nestlings was $0.699 \pm 0.028(\mathrm{n}=1849)$ during the 32 days of fledging (blue line in Figure 2). Most nestling deaths occurred by the first two weeks from hatch, with the highest hazard rate at the $8^{\text {th }}-9^{\text {th }}$ days $(0.033 \pm 0.003)$. As for eggs, Linear Hazard model best fitted to data with equivalent parameter estimates of the unweighted (Lambda = $0.015188 \pm 0.002231 ;$ AIC $=3781.82)$ and weighted $($ Lambda $=0.014103 \pm 0.001019 ;$ AIC $=$ 3781.36) distributions models. The unweighted (solid blue line) and weighted (dashed blue line) Linear Hazard functions of nestling survival times are shown in Figure 3 indicating a more or less regular decline throughout the nestling stage. As for eggs, nestling survival varied significantly across years $\left(\mathrm{Chi}^{2}{ }_{(3)}=24.07 ; \mathrm{p}<0.001\right)$, with the highest survival of 0.838 in 2010 and the lowest in 2009 (survival of 0.771 ) and 2011 (0.729), so that also in this case the annual effect was taken into account.

Nestling survival time was affected by three nest characteristics: height from the ground, nest use frequency and nest-depth, with higher and deeper nests, reused from previous year showing longer nestling survival (Table 1). Three out 6 colony characteristics: avian species richness, human disturbance and colony location, affected nestling survival times (Table 1). High avian species richness, low human disturbance and a peripheral colony location also allowed longer nestling survival times. On ranking the significant nest and colony features, the Akaike model weight showed human disturbance and the location of the colony as the most important variables influencing nestling survival time (Table 2).

\section{DISCUSSION}

Despite its key role in avian population dynamics, little is known about nest site-specific features shaping nest survival in raptors. Research has generally focussed on post-fledging survival of juveniles and survival rates of adults, dealing with the effect of ecological conditions in wintering or breeding areas (Gould and Fuller, 1995; Prugnolle et al., 2003; Grande et al., 2009; Minhoub et al., 2010). Accessibility of nests in a large population has allowed us to provide a first contribution 
revealing the role played by the intrinsic characteristics of nests and colonies on the nest survival of lesser kestrels in a dry cereal steppe habitat. Other nest survival studies have found variation in the daily survival rate throughout the nest cycle, some of them recorded a decline during the laying and/or incubation stage (Sockman, 1997; Peak et al., 2004), whereas others have found a decline during the nestling stage (Burhans et al., 2002; Jehle et al., 2004; Brown and Collopy, 2008). Consistently with the clutch and brood reduction commonly found in raptors (Newton, 1979), our results showed a decline of both egg and nestling survival of lesser kestrel. A massive egg failure in the mid of two fairly constant daily rates happened at the end of the second week of incubation (Figure 2 and 3). More factors than the intrinsic here addressed could be involved to explain such concentrate egg mortality; for instance the sudden and violent spring storms occurred during incubation in 2009 and 2011. Nestling failures were instead concentrated during the early nestling stage when chicks still do not move well and are becoming a manifest visual and acoustic (for loud cheeping) cue to nest predators (Appendix 1).

In addition, egg and nestling survival varied significantly among years as commonly found for survival functions modelling temporal effects (e.g. Nur et al., 2004; Knutson et al., 2007). The two reproductive stages when analyzed taking into account this temporal factor pointed out the significant, yet different, effects of nest and colony building characteristics on reproductive outcome of lesser kestrels nesting in southern Sicily.

Most of the significant features, such as height from the ground, nest depth, reused nests and the presence of jackdaws, are related to the predation pressure faced by lesser kestrels during the nesting season. Role of predation and local composition of predator communities, as in Appendix 1, are the main factors invoked to explain lesser kestrel nesting failures (Serrano et al., 2005b) or differential nest survival in raptors (Brown and Collopy, 2008; Bader and Bednarz, 2009) and birds (Sockman, 1997; Burhans et al., 2002; Drever et al., 2007; Jones and Dieni, 2007; Liebezeit et al., 2009; Rydet et al., 2010). In Gela Plain, kestrel colonies without resident egg-marauders, such as jackdaws, benefited of longer egg survival, although interspecific interactions with this species are multifaceted, with reciprocal advantages in terms of decreased energetic expenditures for vigilance (Campobello et al., 2012). In the study area, the resident jackdaw population is increasing and breeds earlier than the migrating lesser kestrels (Authors unpubl.), so that lesser kestrels are obliged to establish in buildings already occupied. Thus, the vigilance benefits found in Campobello et al. (2012) could emerge as a by-product of this forced coexistence, and as an opportunistic strategy oriented towards shared predators like the magpie (Pica pica) and the raven (Corvus corax).

Consistent with other investigations, nest height was found as one of the most important physical factors affecting nest survival (Nur et al., 2004; Newmark and Stanley, 2011), especially 
during the nestling stage (Brown and Collopy, 2008). The highest nests - especially those in wall crevices - might be safer against unskilled climbers like the western whip snake (Hierophis viridiflavus) or weasel (Mustela erminea); while the deepest nests - especially those under tiles might be safer or more concealed to predatory jackdaws, magpies, or black rats (Rattus rattus). High and deep nest may also be overlooked by vandals and nest-plunders that often raid the colonies (Mascara and Sarà, 2006). As successful nests tend to be reused (Newton, 1979), the significant frequent use found in this study may be explained by the nest characteristics (i.e., nest height and depth) that significantly affected the nest success of kestrel breeding in the Gela Plain.

Solar exposure of nests was another significant variable affecting nest survival, as eggs in westward and southward nests had a higher probability to hatch than those in nests exposed to colder sides or located in the inner part of buildings. Temperature is an important aspect of nest microclimate that influences egg viability (Webb, 1987).

Species richness also exerted a positive effect on egg and nestling survival times of lesser kestrels in the Gela Plain. This factor might play a contrasting role with regard to predation, as more breeding species and their abundance would trigger a dilution of predation risk (Varela et al., 2007), promote earlier detection of predators (Brown and Brown, 1987) or reduce individual investment in vigilance (Campobello et al., 2012). Alternatively, high avian richness may be viewed as an indirect measure of high habitat quality and/or low human disturbance (Danchin et al., 2004).

The lesser kestrel is a species particularly bound to cereal steppe habitats (Forero et al., 1996; Sarà, 2010), in which it selects buildings with suitable cavities for nesting (Franco et al., 2005). The location of the colony was one of the most important variables affecting egg and nestling survival of lesser kestrels in the Gela Plain. Survival time was longer in colonies at the periphery of the agricultural core, i.e. in areas with more natural vegetation and grassland. The other most important factor that negatively affected nest survival in Gela was, however, the human disturbance. Peripheral colonies may have been exposed to less intense disturbance represented by not only agricultural activities, but also proximity to roads and other general human impact, including persecution and nest plundering (Mascara and Sarà, 2006). Despite its classification as an IBA, the Gela Plain does not benefit of a proper wildlife management that should involve conservation actions, including patrolling activities of nest sites of lesser kestrels and other vulnerable steppeland species (Triolo et al., 2011), and prevention of agricultural intensification (Sarà, 2010).

\section{Acknowledgements.}

We thank Rosanna Di Maggio, Rosario Mascara, Stefano Triolo and Joëlle Tysseire for field assistance and an anonymous referee for valuable suggestions that helped to improve the paper. 


\section{References}

Akaike, H. (1973) Information theory and an extension of the maximum likelihood principle. In: Petrov, B.N. and Csaki, F. (eds.), Second Intern. Symposium Information Theory, pp. 267-281. Akademiai Kiado, Budapest.

Bader, T.J. and Bednarz, J.C. (2009) Reproductive Success and Causes of Nest Failures for Mississippi Kites: A Sink Population in Eastern Arkansas? Wetlands, 29(2), 598-606.

Bennetts, R.E., Kitchens, W.M and Dreitz, V.J. (2002) Influence of an extreme high water event on survival, reproduction, and distribution of Snail Kites in Florida, USA. Wetlands, 22(2), 366373.

BirdLife International (2004) Birds in Europe. Population estimates, trends and conservation status. BirdLife International, Cambridge.

Brennan, L. A. and Kuvlesky, W. P. (2005) North American grassland birds: An unfolding conservation crisis? J. Wildl.Manag., 69, 1-13.

Brown, C.R. and Brown, M.B. (1987) Group-living in Cliff Swallows as an advantage in avoiding predators. Behav. Ecol. Sociob., 21, 97-107.

Brown, J.L. and Collopy, M.W. (2008) Nest-Site Characteristics Affect Daily Nest-Survival Rates of Northern Aplomado Falcons (Falco femoralis septentrionalis). The Auk, 125(1), 105-112.

Brunner, A., Celada, C., Rossi, P., and Gustin, M. (2004) Sviluppo di un sistema nazionale delle ZPS sulla base della rete delle IBA (Important Bird Areas). http://www.lipu.it/IBA.

Burhans, D.E., Dearborn, D., Thompson III, F. R. and Faaborg, J. (2002) Factors affecting predation at songbird nests in old fields. J. Wildl. Manag., 66, 240-249.

Campobello, D., Sarà, M. and Hare, J.F. (2012) Under my wing: Lesser Kestrels and Jackdaws derive reciprocal benefits in mixed-species colonies. Behav. Ecol., 23, 425-433. doi:10.1093/beheco/arr207.

Cao, J., He, C.Z., Suedkamp Wells, K.M. Millspaugh, J.J. and Ryan, M.R (2009) Modeling Age and Nest-Specific Survival Using a Hierarchical Bayesian Approach. Biometrics 65, 10521062

Conroy, M.J. and Carroll, J.P. (2009) Quantitative Conservation of Vertebrates. Wiley-Blackwell publishing, Oxford, UK.

Cramp. S. and Simmons, K.E.L. (1980) The birds of the Western Palaearctic. Vol. 2. Oxford University Press, Oxford, NY.

Danchin, E., Giraldeau, L.A., Valone, T.J. and Wagner, R.H. (2004) Public information: from nosy neighbors to cultural evolution. Science, 305, 487-491

Dinsmore, S.J., White, G.C. and Knopf, F.L. (2002) Advanced techniques for modeling avian nest survival. Ecology, 83, 3476-3488. 
Donald, P.F., Green, R.E. and Heath, M.F. (2001) Agricultural intensification and the collapse of Europe's farmland bird populations. Proc. Royal Soc. London Series B - Biological Sciences, 268, 25-29.

Donovan, T.M., Thompson III, F.R., Faaborg, J. and Probst, J.R. (1995) Reproductive success of migratory birds in habitat sources and sinks. Conserv. Biol., 9, 1380-1395.

Drever, M.C., Nudds, T.D. and Clark, R.G. (2007) Agricultural policy and nest success of prairie ducks in Canada and the United States. Avian Conservation and Ecology - Écologie et conservation des oiseaux 2(2), 5 http://www.ace-eco.org/vol2/iss2/art5/.

Forero, M.G., Tella, J.L., Donázar, J.A. and Hiraldo, F. (1996) Can interspecific competition and nest site availability explain the decrease of lesser kestrel Falco naumanni populations? Biol. Conserv., 78, 289-293.

Fox, G.A. (2001) Failure-time analysis: studying times to events and rates at which events occur. In: Scheiner, S.M. and Gurevitch, J. (eds), Design and analysis of ecological experiments, pp. 235-266. Oxford University Press, Oxford.

Franco, A.M.A., Marques, J.T., and Sutherland, W. (2005) Is nest-site availability limiting Lesser Kestrel populations? A multiple scale approach. Ibis, doi: 10.1111/j.1474-919x.2005.00437.x

Gould, W.R. and Fuller, M. (1995) Survival and population size estimation in Raptor studies: a comparison of two methods. J. Raptor Res., 29(4), 256-264.

Grande, J.M., Serrano, D., Tavecchia, G., Carrete, M., Ceballos, O., Dìaz-Delgado, R., Tella, J.L. and Donàzar J.A. (2009) Survival in a long-lived territorial migrant: effects of life-history traits and ecological conditions in wintering and breeding areas. Oikos, 118, 580-590,

Hansell, M.H. (2000) Bird nests and construction behaviour. Cambridge University Press, Cambridge.

Heisey, D.M., Shaffer, T.L. and White, G.C. (2007) The abcs of nest survival: theory and application from a biostatistical perspective. In: Jones S.L. and Geupel G.R. (eds), Beyond Mayfield: Measurements of Nest-Survival data. Studies in Avian Biology no. 34, pp. 13-33. Cooper Ornithological Society, Pennsylvania.

Hood S.L. and Dinsmore S.J. (2007) The influence of habitat on nest survival of Snowy and Wilson's plovers in the lower Laguna Madre region of Texas. In: Jones S.L. and Geupel G.R. (eds), Beyond Mayfield: Measurements of Nest-Survival data. Studies in Avian Biology no. 34, pp. 24-135. Cooper Ornithological Society, Pennsylvania.

Hosmer, D.W. and Lemeshow, S. (1999) Applied survival analysis: regression modeling of time to event data. John Wiley, New York.

Jehle, G., Yackel Adams, A.A., Savidge, J.A. and Skagen, S.K. (2004) Nest survival estimation: a review of alternatives to the Mayfield estimator. Condor, 106, 472-484.

Jones, S.L. and Dieni, J.S. (2007) The relationship between predation and nest concealment in mixed-grass prairie passerines: an analysis using program MARK. In: Jones S.L. and Geupel G.R. (eds), Beyond Mayfield: Measurements of Nest-Survival data. Studies in Avian Biology no. 34, pp. 117-123. Cooper Ornithological Society, Pennsylvania. 
Johnson, D.H. (2007) Estimating nest success: a guide to the methods. In: Jones S.L. and Geupel G.R. (eds), Beyond Mayfield: Measurements of Nest-Survival data. Studies in Avian Biology no. 34, pp. 65-72. Cooper Ornithological Society, Pennsylvania.

Jones, S.L. and Geupel, G.R. (2007) Beyond Mayfield: Measurements of Nest-Survival data. Studies in Avian Biology no. 34. Cooper Ornithological Society, Pennsylvania.

Knutson L.G., Gray B.R., Meier M.S. (2007) Comparing the effects of local, landscape, and temporal factors on forest bird nest survival using logistic-exposure models. In: Jones S.L. and Geupel G.R. (eds), Beyond Mayfield: Measurements of Nest-Survival data. Studies in Avian Biology no. 34, pp. 105-116. Cooper Ornithological Society, Pennsylvania.

IUCN (2011) IUCN Red List of Threatened Species. Version 2011.2. www.iucnredlist.org.

Liebezeit, J.R., Kendall, S.J., Brown, S., Johnson, C.B., Martin, P., McDonald, T.L., Payer, D.C., Rea, C.L., Streever, B., Wildman, A.M. and Zack, S. (2009) Influence of human development and predators on nest survival of tundra birds, Arctic Coastal Plain, Alaska. Ecol Appl., 19(6), 1628-1644.

Liven-Schulman, I., Leshem, Y., Alon, D. and Yom Tov, Y. (2004) Causes of population decline of the Lesser kestrel Falco naumanni in Israel. Ibis, 146, 145-152.

Mayfield, H.F. (1975) Suggestions for calculating nest success. Wilson Bull., 87, 456-466.

Mascara, R. and Sarà, M. (2006) Densità e biologia riproduttiva del Grillaio Falco naumanni nella piana di Gela (Sicilia). Avocetta, 30, 51-59.

Mihoub, J.B., Gimenez, O., Pilard, P. and Sarrazin, F. (2010) Challenging conservation of migratory species: Sahelian rainfalls drive first-year survival of the vulnerable Lesser Kestrel Falco naumanni. Biol. Conserv., 143, 839-847.

Negro, J.J., Donázar, J.A., Hiraldo, F., Hernández, L.M. and Fernández, M.A. (1993) Organochlorine and heavy metal contamination in non-viable eggs and its relation to breeding success in a Spanish population of lesser kestrel Falco naumanni. Environm. Poll., 82, 201205.

Newmark, W.D. and Stanley, T.R. (2011) Habitat fragmentation reduces nest survival in an Afrotropical bird community in a biodiversity hotspot. PNAS, doi:10.1073/pnas.1104955108.

Newton, I. (1979) Population Ecology of Raptors. T \& AD Poyser, Berkhamsted.

Nur, N., Holmes, A.L. and Geupel, G.R. (2004) Use of survival time analysis to analyze nesting success in birds: an example using Loggerhead Shrikes. Condor, 106, 457-471.

Ortego, J., Zapero, L., Calabuig, G., Cordero, P.J. and Aparicio, J.M. (2009) Physiological response to stress in fledgling Lesser Kestrels Falco naumanni: the role of physical condition, sex and individual genetic diversity. Ibis, 151, 559-567.

Pain, D.J. and Pienkowski, M.W. (1997) Farming and Birds in Europe: The Common Agricultural Policy and its Implications for Bird Conservation. Academic Press, London.

Peak, R.G., Thompson III, F.R. and Shaffer, R.L. (2004) Factors Affecting Songbird Nest Survival in Riparian forests in a Midwestern agricultural landscape. Auk, 121(3), 726-737, 
Prugnolle, F., Pilard, P., Brun, L. and Tavecchia, G. (2003) First-year and adult survival of the endangered Lesser Kestrel Falco naumanni in southern France. Bird Study, 50, 68-72

Rodríguez, C. and Bustamante, J. (2003) The effect of weather on lesser kestrel breeding success: can climate change explain historical population declines? J. Animal Ecol., 72, 793-810.

Rotella, J.J., Dinsmore, S.J. and Shaffer, T.L. (2004) Modeling nest-survival data: a comparison of recently developed methods that can be implemented in MARK and SAS. Animal Biodiversity and Conservation, 27(1), 187-205.

Rotella, J. (2007) Modeling nest-survival data: recent improvements and future directions. In: Jones S.L. and Geupel G.R. (eds), Beyond Mayfield: Measurements of Nest-Survival data. Studies in Avian Biology no. 34, pp. 145-148. Cooper Ornithological Society, Pennsylvania.

Ryder, T.B., Reitsma, R., Evans, B. and Marra, P.P. (2010). Quantifying avian nest survival along an urbanization gradient using citizen- and scientist-generated data. Ecol. Appl., 20(2), 419426.

Saab, V.A., Russell, R.E., Rotella, J. and Dudley, J.G. (2011) Modeling Nest Survival of CavityNesting Birds in Relation to Postfire Salvage Logging. J. Wildl. Manag., 75(4), 794-804.

Sarà, M. (2008) Breeding abundance of threatened raptors as estimated from occurrence data. Ibis, 150, 766-778.

Sarà, M. (2010) Climate and land-use changes as determinants of Lesser Kestrel Falco naumanni abundance in Mediterranean cereal steppes (Sicily). Ardeola, 57, 3-22.

Serrano, D., Tella, J.L. and Donazár, J.A. (2001) Factors affecting breeding dispersal in the facultatively colonial Lesser Kestrel: individual experience vs. conspecific cues. J. Animal Ecol., 70, 568-578.

Serrano, D., and Tella, J.L. (2003) Dispersal within a spatially structured population of Lesser Kestrels: the role of spatial isolation and conspecific attraction. J. Animal Ecol., 72, 400-410.

Serrano, D., Oro, D., Ursua, E. and Tella, J.L. (2005a) Colony size selection determines adult survival and dispersal preferences: allee effects in a colonial bird. American Naturalist 166, 22-31.

Serrano, D., Tella, J.L. and Ursúa, E. (2005b) Proximate causes and fitness consequences of hatching failure in Lesser Kestrels Falco naumanni. J. Avian Biol., 36, 242-250.

Sockman, K.W. (1997) Variation in life-history traits and nest-site selection affects risk of nest predation in the California Gnatcatcher. Auk, 114, 324-332.

StatSoft (2007) STATISTICA (data analysis software system), version 8.0. Statsoft Incorporated, Tulsa.

Tella, J.L., Hiraldo, F., Donazár, J.A. and Negro, J.J. (1996) Costs and benefits of urban nesting in lesser kestrel. In: Bird, D.M., Varland, D. and Negro, J.J. (eds), Raptors in Human Landscapes: Adaptations to Built and Cultivated Environments, pp. 53-60. Academic Press, London. 
Triolo, S., Campobello, D. and Sarà, M. (2011) Diurnal habitat suitability for a Mediterranean steppeland bird, identified by Ecological Niche Factor Analysis. Wildl. Res., 38, 152-162.

Tucker, G.M., and Heath, M.F. (1994) Birds in Europe their conservation status. Conservation Series 3. BirdLife International, Cambridge.

Vickery, P.D. and Herkert, J.R. (2001) Recent advances in grassland bird research: Where do we go from here? Auk, 118, 11-15.

Varela, S.A.M., Danchin, E. and Wagner, R.H. (2007) Does predation select for or against avian coloniality? - A comparative analysis. J. Evol. Biol., 20, 1490-1503.

Webb, D. (1987) Thermal tolerance of avian embryos: a review. Condor, 89, 874-89. 
Nest characteristics

Egg stage

Nestling stage

$\begin{array}{lcccccc} & \mathrm{Chi}^{2} & \mathrm{df} & \mathrm{p} & \mathrm{Chi}^{2} & \mathrm{df} & \mathrm{p} \\ \text { Nest position } & 0.325 & 1 & 0.568 & 0.001 & 1 & 0.970 \\ \text { Solar exposure } & 16.847 & 4 & \mathbf{0 . 0 0 2} & 5.237 & 4 & 0.264 \\ \text { H from the ground } & 3.998 & 1 & \mathbf{0 . 0 4 5} & 15.262 & 1 & <\mathbf{0 . 0 0 1} \\ \text { Nest height } & 0.231 & 1 & 0.564 & 0.074 & 1 & 0.785 \\ \text { Nest width } & 0.093 & 1 & 0.714 & 0.016 & 1 & 0.900 \\ \text { Nest depth } & 1.481 & 1 & 0.224 & 7.911 & 1 & \mathbf{0 . 0 0 5} \\ \text { Nest volume } & 0.026 & 1 & 0.873 & 1.418 & 1 & 0.234 \\ \text { Use frequency } & 0.034 & 1 & 0.853 & 10.122 & 1 & \mathbf{0 . 0 0 1} \\ & & & & & & \\ \text { Colony characteristics } & & & & & & \\ & \mathrm{Chi} \mathbf{i}^{2} & \mathrm{df} & \mathrm{p} & \mathrm{Chi} & \\ \text { Colony location } & 22.304 & 1 & \mathbf{0 . 0 0 1} & 34.315 & 1 & \mathbf{d} \\ \text { Colony size } & 1.645 & 1 & 0.200 & 2.790 & 1 & 0.095 \\ \text { Presence/absence of jackdaw } & 5.338 & 1 & \mathbf{0 . 0 2 1} & 1.008 & 1 & 0.315 \\ \text { Avian species richness } & 4.485 & 1 & \mathbf{0 . 0 3 4} & 10.822 & 1 & \mathbf{0 . 0 0 4} \\ \text { Competitor/predator score } & 1.249 & 1 & 0.264 & 1.977 & 1 & 0.160 \\ \text { Human-disturbance index } & 12.340 & 1 & \mathbf{0 . 0 0 1} & 36.529 & 1 & <\mathbf{0 . 0 0 1}\end{array}$

Table 1 Results of Cox's proportional hazard models stratified by year and applied to characteristics of nests and colonies in the Gela Plain. Ps $\leq 0.05$ (in bold) indicate those variables that best predicted the survival time of lesser kestrel eggs and nestlings in the Gela plain during the 3-year study period. 


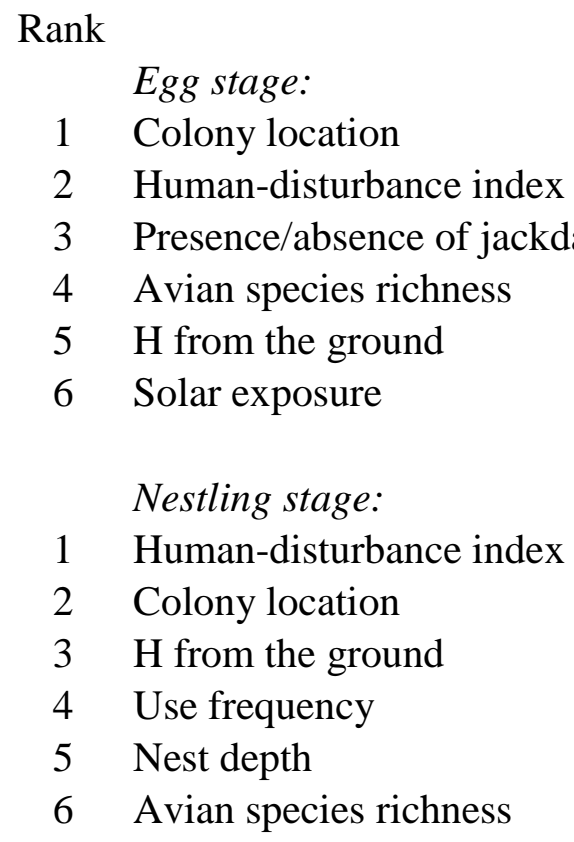

$\begin{array}{ccc}\text { AIC } & \Delta \text { AIC } & w_{i} \\ & & \\ 8588.10 & 0.00 & 0.993 \\ 8598.24 & 10.14 & 0.006 \\ 8605.08 & 16.98 & 2 \mathrm{E}-04 \\ 8605.96 & 17.86 & 1 \mathrm{E}-04 \\ 8606.56 & 18.46 & 1 \mathrm{E}-04 \\ 8609.74 & 21.64 & 2 \mathrm{E}-05 \\ & & \\ & & \\ 4919.72 & 0.00 & 0.751 \\ 4921.94 & 2.22 & 0.248 \\ 4940.98 & 21.26 & 2 \mathrm{E}-05 \\ 4946.12 & 26.40 & 1 \mathrm{E}-06 \\ 4947.96 & 28.24 & 6 \mathrm{E}-07 \\ 4952.14 & 32.42 & 7 \mathrm{E}-08\end{array}$

Table 2 Ranking of variables significantly affecting egg and nestling survival times of lesser kestrels in the Gela Plain. Models with a lower $\triangle \mathrm{AIC}$ and a greater Akaike weight $\left(w_{i}\right)$ have more support. 
Egg stage Nestling stage

Colony residents

Reptiles

Western whip snake, Hierophis viridiflavus

$++\quad ?$

Birds

Magpie, Pica pica

Jackdaw, Corvus monedula

Barn owl, Tyto alba

Little owl, Athene noctua

European kestrel, Falco tinnuculus

$\begin{array}{cc}+++ & +++ \\ ++ & ? \\ \mathrm{n} & ++ \\ \mathrm{n} & ? \\ \mathrm{n} & ?\end{array}$

Mammals

Black rat, Rattus rattus

Garden dormouse, Eliomys quercinus

Weasel, Mustela erminea

$\begin{array}{cc}+++ & +++ \\ + & ? \\ + & ++\end{array}$

Transients (\$)

Lanner falcon, Falco biarmicus

Common Buzzard, Buteo buteo

n $\quad+$

Raven, Corvus corax

$\mathrm{n}+$

$++\quad++$

Human beings, Homo sapiens

? $\quad++$

Appendix 1 Predator community recorded in the colonies affecting the nest success of lesser kestrel in the dry cereal habitats of Gela Plain. + occasional, ++ frequent, +++ very frequent predation, ? probable predation not recorded yet, $\mathrm{n}=$ no predation. (\$) For the sake of completeness, also predators not considered in the statistical analysis of such study, because not resident in the colonies, have been reported. 


\section{Figure captions}

Figure 1 The Giaurone house, a typical abandoned building in the Gela Plain that hosted $29 \pm 7$ (mean $\pm \mathrm{SD}$ ) lesser kestrel nest sites during the 3-year study. In the photo inserts, a male lesser kestrel entering his nest under roof tiles (up), and 16-18 day old nestlings inside a nest hole (below).

Figure 2 Cumulative proportions of surviving eggs (red line) and nestlings (blue line) as resulting from raw observed data for all years combined.

Figure 3 Linear Hazard survival models of lesser kestrel eggs (red) and nestlings (blue) in the Gela Plain. Solid lines = unweighted functions; dashed lines = weighted functions (see text). 




Figure 1 


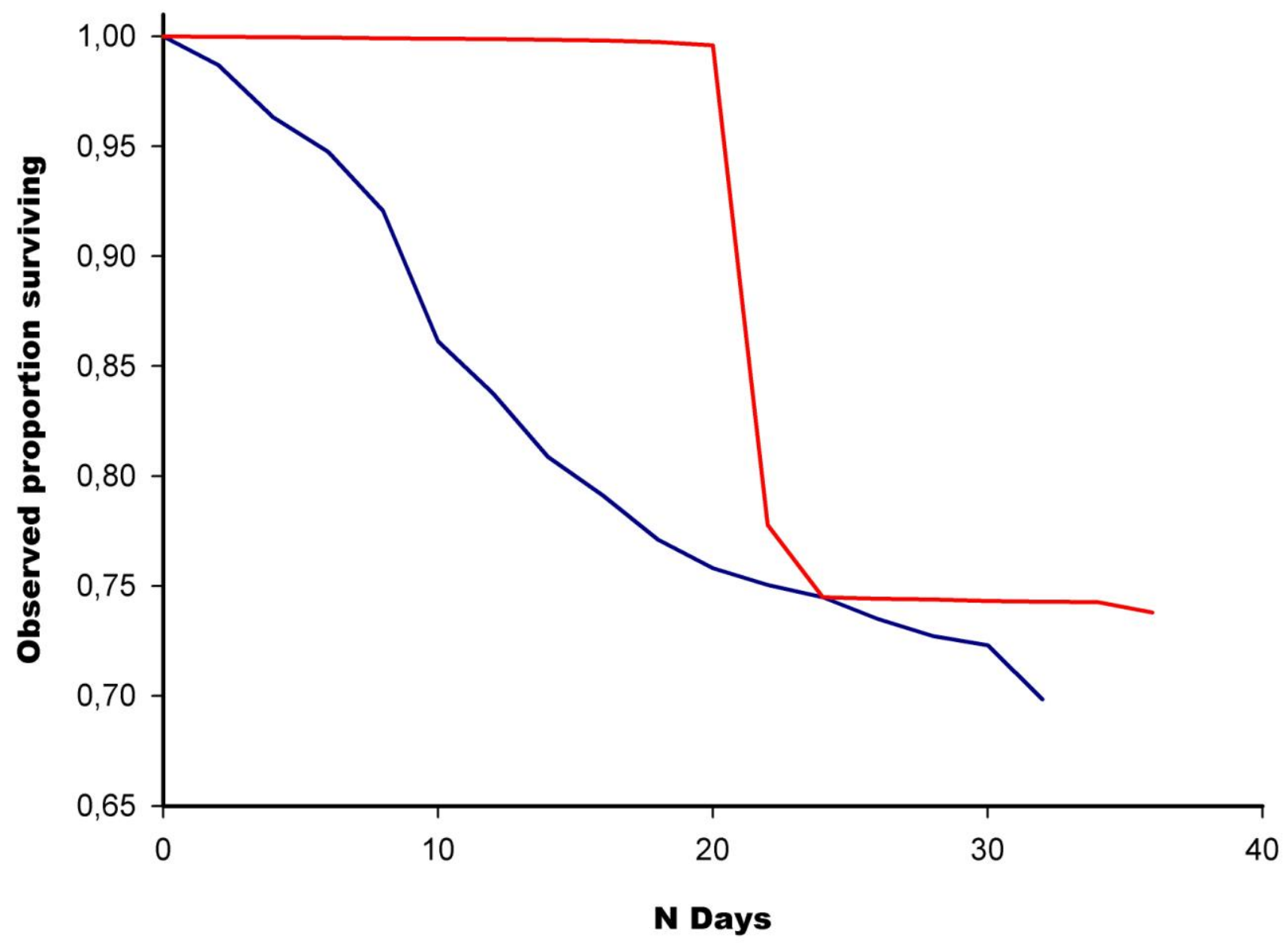

Figure 2 


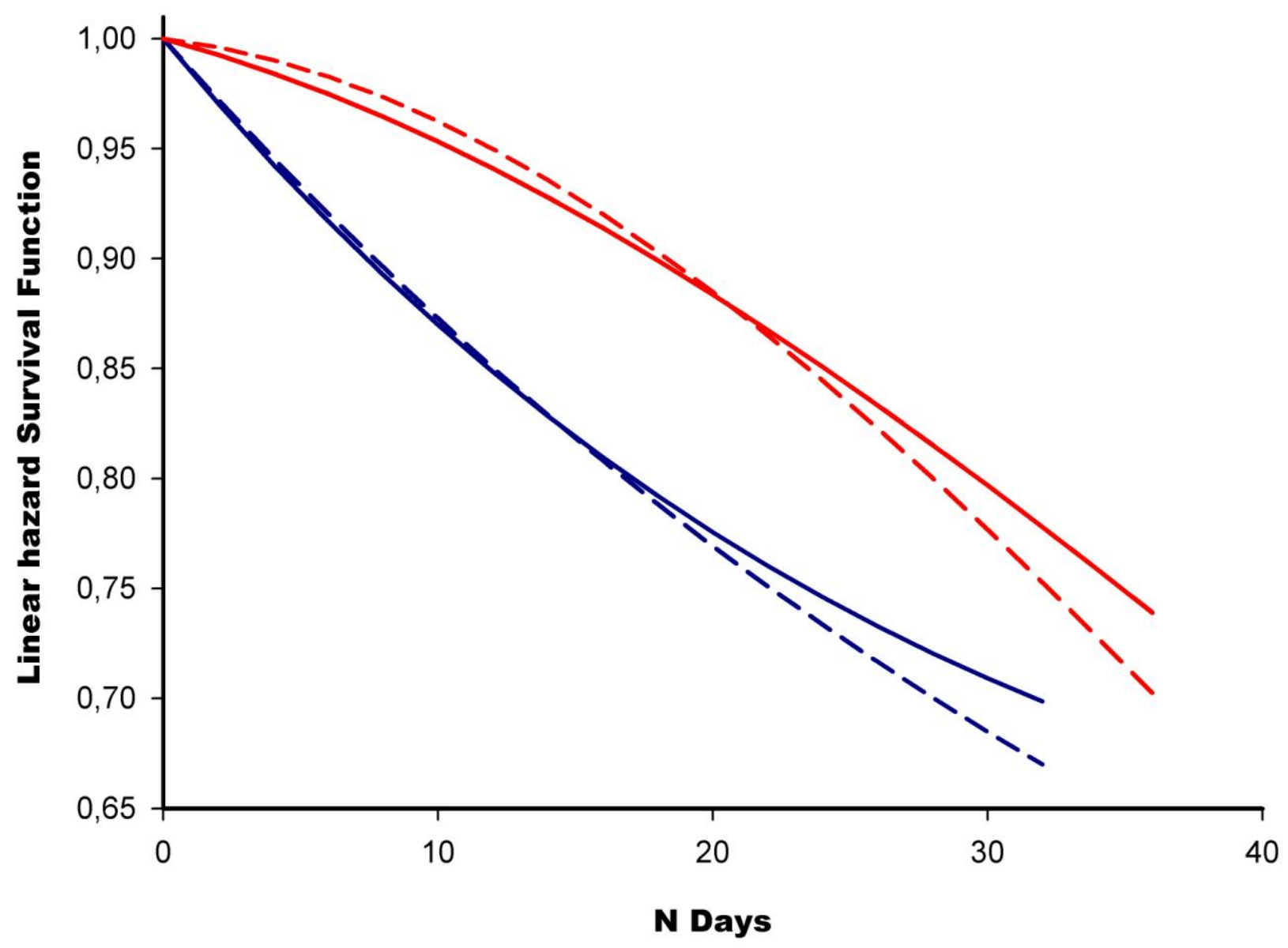

Figure 3 